\title{
True Expense Ratio and True Alpha of Imperfect Diversification: Evidence from Stock Market in Bangladesh
}

\author{
Md Sajib Hossain ${ }^{1}$ \\ ${ }^{1}$ Assistant Professor, Department of Finance, University of Dhaka, Bangladesh \\ Correspondence: Md Sajib Hossain, Assistant Professor, Department of Finance, University of Dhaka, \\ Bangladesh. Tel: 880-199-2243-7548. E-mail: sajibfin06@du.ac.bd
}

Received: August 8, 2020

Accepted: September 16, 2020

Online Published: October 5, 2020

doi:10.5539/ijef.v12n11p21

URL: https://doi.org/10.5539/ijef.v12n11p21

\begin{abstract}
Actively managed funds try to outperform by deviating from passive benchmarks such as the S\&P 500, leading to imperfect diversification and higher idiosyncratic volatility. The idiosyncratic volatility imposes an additional cost to the shareholders. In this study, using data of all the closed-end mutual funds listed with Dhaka Stock Exchange (DSE) from 2012 to 2019, I have attempted to quantify this higher idiosyncratic volatility as an additional expense on the portfolio and then estimate true expense ratio and true net alpha of the actively managed funds as a new measure for imperfect portfolio diversification. The study finds that mean volatility cost of the funds is $1.42 \%$ which is on an average around $89 \%$ of the explicit expense ratio and the findings that volatility costs are not strongly correlated with other performance measures such as Sharpe, Treynor or information ratios provides additional information about the fund performance. Moreover, when volatility cost is adjusted to traditional Jensen alpha measure to find a true net alpha of the funds, rankings of the funds significantly change and two alpha measures are not strongly positively correlated, suggesting new information about the fund performance.
\end{abstract}

Keywords: expense ratio, volatility costs, mutual funds, idiosyncratic risk, Alpha

\section{Introduction}

Several studies have concluded that an average actively managed fund performs almost same as low cost indexed portfolio before fees and expenses but loses to a low cost index fund net of all fees and expenses (Jensen, 1968; Petajisto, 2013). Active managers deviate from the passive benchmark on the premise that mispricing exists in the market and they can successfully exploit whatever security mispricing might exist. Such deviation from the benchmark portfolio introduces two new things in the portfolio; higher management expenses and higher idiosyncratic volatility. Existing literature on how fund management fees and higher volatility affect the performance of mutual fund demonstrated that on average, active investment managers underperform their benchmarks by an amount approximately equal to their fees (Jensen, 1968; Elton et al., 1993; Malkiel, 1995; Gruber, 1996; Carhart, 1997; Wermers, 2000; Pastor \& Stambaugh, 2002; and Fama \& French, 2010). Yet, active managers can have superior skill that might justify higher fees, and some managers might be more skilled than others. However, empirical evidence suggests that skill does not equate to average performance, gross or net of fees (Berk \& Green, 2004; Pastor \& Stambaugh, 2012; Stambaugh, 2014; and Pastor, Stambaugh, \& Taylor, 2015)

Contradictory empirical evidence is also observed. For example, Kacperczyk, Sialm, and Zheng (2005) report that funds having more concentrated portfolios perform better. Cremers and Petajisto (2009) find that funds, whose active share is higher compared to underlying portfolio of their benchmark, perform better. Following Cremers and Petajisto (2009), Petajisto (2013) divided active managers into several categories based on both Active Share, and tracking error. Active Share measures mostly stock selection and tracking error measures mostly exposure to systematic. He found that "most active stock pickers outperformed their benchmark indices even after fees, whereas closet indexers underperformed. These patterns held during the 2008-09 financial crises and within market-cap styles." Cremers et al. (2016) report the similar result in the subsequent study. Similarly Amihud and Goyenko (2013) find better performance among funds that have lower explanatory power measure in terms of R2 from benchmark regressions. Pastor, Stambaugh, and Taylor (2017) examined the relation between trading and subsequent benchmark adjusted performance and they report a positive relation 
benchmark-adjusted return. Moreover, they find that compared to cross-sectional relation, time-series relation between turnover and performance is stronger.

In the existing literature, idiosyncratic volatility due to imperfect diversification is incorporated in traditional measure of mutual funds' performance such as the Sharpe ratio, the information ratio, and the M-2 or M-3 measure. A possible disadvantage of such measure is that a fund might appear to have beaten the benchmark if it generates net alpha. But net alpha comes at increased volatility and if this increased volatility can be converted into expense, then total expense could be higher and true net alpha can be negative. Existing literature of performance measure does not quantify this idiosyncratic volatility as measure of additional cost of active management. In this research, I will attempt to quantify this higher idiosyncratic volatility as additional expense on the portfolio and then estimate true expense ratio and true net alpha of the actively managed funds.

The rest of the paper is organized as follows; section two provides a theoretical framework for measuring the true expense ratio and true alpha of imperfect diversification, section three explains the data of the study, section four presents the results and section five is the conclusion.

\section{Measuring True Expense Ratio and True Alpha of Imperfect Diversification}

To generate the abnormal return, active managers underweight or overweight many of the stocks in the benchmark, resulting in imperfect diversification and higher idiosyncratic volatility. The idiosyncratic volatility imposes additional cost to the shareholders that has not been quantified in the existing literature of performance measure of mutual fund. In this research I will try to quantify the cost of imperfect diversification and attempt to show that when cost of idiosyncratic risk is added to the explicit cost of portfolio management, true expense ratio of portfolio manager be much higher. Then I will show how true net alpha can be measured from the true expense ratio of imperfect diversification.

A passive fund manager can move along the capital market line by investing $\beta$ fraction in the market index and $1-\beta$ in the risk-free security to generate return $\widetilde{R_{P t}}$

$$
\begin{gathered}
\widetilde{R_{P t}}=\beta \widetilde{r_{M t}}+(1-\beta) r_{f t} \\
=r_{f t}+\beta\left(\tilde{r}_{M t}-r_{f t}\right)
\end{gathered}
$$

If $e_{P}$ is the operating expense charged by the passive manager for asset management fee and other costs, and then $R_{P t}$ is used to denote gross portfolio return while $\widetilde{r_{P t}}$ is used to denote portfolio return net of expenses so that we have

$$
\begin{gathered}
\widetilde{r_{P t}}=\widetilde{R_{P t}}-e_{p} \\
\widetilde{r_{P t}}=r_{f t}+\beta\left(\tilde{r}_{M t}-r_{f t}\right)-e p
\end{gathered}
$$

In contrast to passive manager, an active manager deviates from the passive benchmark, introducing non-market return $\tilde{r}_{N t}$ into the portfolio return

$$
\tilde{R}_{A t}=r_{f t}+\beta\left(\tilde{r}_{M t}-r_{f t}\right)+\tilde{r}_{N t}
$$

If the non-market return is decomposed into its average, $\theta_{A}$ which measures the abnormal return on the portfolio and $\tilde{r}_{\epsilon t}$ which measures mean-zero random components, then we have

$$
\tilde{r}_{N t}=\theta_{A}+\tilde{r}_{\epsilon t}
$$

It can be written as

$$
\tilde{R}_{A t}=r_{f t}+\beta\left(\tilde{r}_{M t}-r_{f t}\right)+\theta_{A}+\tilde{r}_{\epsilon t}
$$

The return reported to the shareholders during a period t is net of expenses

$$
\begin{gathered}
\widetilde{r}_{A t}=\widetilde{R_{A t}}-e_{A} \\
\widetilde{r}_{t}=r_{f t}+\beta\left(\tilde{r}_{M t}-r_{f t}\right)+\theta_{A}+\tilde{r}_{\epsilon t}-e_{A} \\
=r_{f t}+\beta\left(\tilde{r}_{M t}-r_{f t}\right)+\alpha_{A}+\tilde{r}_{\epsilon t}
\end{gathered}
$$

Here $\alpha_{A}=\theta_{A}-e_{A}$ is the abnormal return available to the investors net of expenses. The average return during a measurement period is

$$
\bar{r}_{A}=\alpha_{A}+\bar{r}_{f}+\beta\left(\bar{r}_{M}+\bar{r}_{f}\right)
$$

The portfolio's deviation from the underlying benchmark leads to imperfect diversification and idiosyncratic volatility, $\sigma_{\epsilon}^{2}$, in its returns. As a result, the total risk of active fund manager's returns using single index model is

$$
\sigma^{2}=\beta^{2} \sigma_{M}^{2}+\sigma_{\epsilon}^{2}
$$


The deviation from the benchmark portfolio can be seen in the reduced $\mathrm{R}^{2}$ :

$$
R^{2}=1-\frac{\sigma_{\epsilon}^{2}}{\sigma^{2}}
$$

and the increased idiosyncratic and total volatilities due to imperfect diversification which show up in the Sharpe ratio and information ratio of the investor returns:

$$
\begin{gathered}
\text { Sharpe Ratio }=\frac{\bar{r}-r_{f}}{\sigma}=\frac{\alpha+\beta\left(\overline{r_{M}}-\bar{r}_{f}\right)}{\sqrt{\beta^{2} \sigma_{M}^{2}+\sigma_{\epsilon}^{2}}} \\
\text { And Information ratio }=\frac{\alpha}{\sigma_{\epsilon}}
\end{gathered}
$$

As a result, other things being the same, the higher is the idiosyncratic volatility $\sigma_{\epsilon}$, the lower is the Sharpe and information ratios. An alternative way to measure the effect of imperfect diversification is through the reduced return due to increased volatility. Specifically, the terminal wealth after $\mathrm{n}$ periods is:

$$
\begin{gathered}
W_{T}=W_{0}\left(1+r_{1}\right)\left(1+r_{2}\right)\left(1+r_{3}\right) \ldots \ldots \ldots\left(1+r_{n}\right) \\
\text { Or } \quad W_{T}=W_{0}(1+g)^{n}
\end{gathered}
$$

Here, $g$ is the geometric mean return. For a given average (arithmetic mean) return, the higher the volatility, the lower the geometric mean return and the lower the terminal wealth. If the returns have a normal distribution then the expected geometric mean return is related to the arithmetic mean return as

$$
E(g)=E(r)-\frac{1}{2} \sigma^{2}
$$

While individual security returns may not be normally distributed, guided by central limit theorem it is safe to assume that returns of diversified portfolios are normally distributed. The ex-post counterpart of this equation is:

$$
g=\bar{r}-\frac{1}{2} \sigma^{2}
$$

Substituting equations (11) and (12) into equation (19) we get

$$
\begin{gathered}
g=\alpha+r_{f}+\beta\left(\bar{r}_{M}-\bar{r}_{f}\right)-\frac{1}{2}\left(\beta^{2} \sigma_{M}^{2}+\sigma_{\epsilon}^{2}\right) \\
=\alpha-\frac{1}{2} \sigma_{\epsilon}^{2}+r_{f}+\beta\left(\bar{r}_{M}-\bar{r}_{f}\right)-\frac{1}{2} \beta^{2} \sigma_{M}^{2}
\end{gathered}
$$

This equation 21 gives a clear expression of the costs and benefits of imperfect portfolio management. The benefit is access to the management skill $\alpha$ of active manager and the cost is the management fee which is already incorporated into $\alpha$ and the increased volatility $\sigma_{\epsilon}$. But existing measure of active portfolio performance such as Jensen Alpha only reports alpha net of explicit expenses such as management expense and operating expenses. In my opinion true net alpha should incorporate both the explicit costs and implicit cost measured by idiosyncratic volatility associated with imperfect diversification. To the best of my knowledge in the portfolio performance literature, no researcher has incorporated this idiosyncratic volatility of imperfect diversification as additional cost on the shareholders and attempted to find out true expense ratio and true net alpha.

The true net alpha, taking the volatility associated with active management into account, is $\alpha-\frac{1}{2} \sigma_{\epsilon}^{2}$. Alternatively, it can be said that the true expense ratio consists of reported expense ratio plus the cost of imperfect diversification $\frac{1}{2} \sigma_{\epsilon}^{2}$. The objective of this research will be to measure the cost associated with increased volatility due to imperfect diversification, $\frac{1}{2} \sigma_{\epsilon}^{2}$ and then finding the true expense ratios of active management taking both the explicit and implicit cost and then true net alpha using the real data.

\section{Data}

The data used in this study were taken from the Dhaka Stock Exchange (DSE) research department. Month-end closing prices of the closed-end mutual funds that have been listed and continuously traded from January 2012 to June 2019 have been taken and adjusted for any cash dividend/stock dividend to estimate the monthly return. DSE broad Index (DSEX) has been taken as a proxy for the market return estimation. For the risk-free rate, the average monthly yield of the 91-day Bangladesh government Treasury bill has taken as a proxy.

\section{Results}

Table 1 shows the results of the 9 years sample (see details of individual funds in table 1 in the appendix). The 
average size of the mutual funds is 2037 million taka with a minimum size of 727 million taka and a maximum size of 8535 million taka. The expense ratio includes management fees, custodian fees, trustee fees, fees to stock exchanges, and other administration fees. The mean expenses ratio is $1.70 \%$ of NAV measured at fair value at the end of the reporting year. To estimate the volatility costs, the idiosyncratic component of the return series is computed using the following equation

$$
€_{t}=r_{f t}-\left[r_{f t}+\alpha+\beta\left(r_{M t}-r_{f t}\right)\right]
$$

The volatility cost (Vol Cost") then is calculated as $1 \frac{1}{2} \sigma_{\epsilon}^{2}$. The true expense ratio (True Exp Ratio") is the sum of reported expense ratio and the volatility cost. As observed in the Table 1, the volatility costs ranges from $0.52 \%$ to $3.6 \%$ with a mean value of $1.42 \%$.

Table 1. Characteristics of mutual funds (from 2012 to 2019): size, expense ratio, volatility cost and true expense ratio

\begin{tabular}{cccccccc}
\hline Particulars & $\mathrm{N}$ & NAV (Mill Tk) & Exp (Mill Tk) & Exp Ratio (\%) & Vol Cost & Vol Cost/Exp Ratio & True Exp Ratio \\
\hline Mean & 108 & 2037.36 & 35.36 & $1.70 \%$ & $1.42 \%$ & $88.61 \%$ & $3.12 \%$ \\
Median & 108 & 1352 & 26 & $1.64 \%$ & $1.40 \%$ & $84.75 \%$ & $3.03 \%$ \\
Maximum & 108 & 8535 & 203 & $2.38 \%$ & $3.60 \%$ & $241.65 \%$ & $5.09 \%$ \\
Minimum & 108 & 727 & 11 & $1.03 \%$ & $0.52 \%$ & $28.24 \%$ & $2.36 \%$ \\
\hline
\end{tabular}

The volatility cost as a percentage of the explicit expense ratio is almost $89 \%$ (sees details of individual funds in table 2 in the Appendix). When volatility costs are added to the explicit expense ratios, the true expense ratio gets almost doubled. This is an important finding because when investors use traditional performance measures such as Sharpe ratio, Jensen Alpha or Treynor ratio, they fail to consider the true expense of the funds that they are bearing both in the form of explicit expense ratio (management fees) and in the form of implicit cost (volatility costs). The results in table 1 shows that this implicit cost is quite significant compared to the explicit expense ratio of the actively managed funds.

Moreover, the volatility cost is strongly negatively correlated $R^{2}$ indicating that it is the outcome of imperfect diversification.

In the context of CAPM, ex-post average return of funds can be defined as

$$
\begin{aligned}
\bar{r}_{A} & =\alpha_{A}+\bar{r}_{f}+\beta\left(\bar{r}_{M}-r_{f}\right) \\
\alpha_{A} & =\bar{r}_{A}-\left[\bar{r}_{f}+\beta\left(\bar{r}_{M}-r_{f}\right)\right]
\end{aligned}
$$

Now true alpha of the fund can be estimated after deducting volatility costs from the equation 24

$$
\text { True } \alpha_{A}=\bar{r}_{A}-\left[\bar{r}_{f}+\beta\left(\bar{r}_{M}-r_{f}\right)\right]-\frac{1}{2} \sigma_{\epsilon}^{2} .
$$

Table 2 shows the summary of the results estimated from equations 24 and 25 along with other performance measures. The results show that average funds were creating value for the investors by generating positive alpha.

Table 2. Summary of performance of mutual funds (from 2012 to 2019): Jensen Alpha, True Alpha, Sharpe Ratio, Information Ratio and Treynor Ratio

\begin{tabular}{ccccccc}
\hline Particulars & $\mathrm{N}$ & Jensen Alpha & True Alpha & Sharpe Ratio & Information Ratio & Treynor Ratio \\
\hline Mean & 108 & $0.078 \%$ & $-1.340 \%$ & $-0.423 \%$ & $1.632 \%$ & $-0.175 \%$ \\
Median & 108 & $0.110 \%$ & $-1.263 \%$ & $-0.376 \%$ & $1.951 \%$ & $-0.153 \%$ \\
Maximum & 108 & $0.602 \%$ & $-0.251 \%$ & $1.124 \%$ & $7.103 \%$ & $1.184 \%$ \\
Minimum & 108 & $-0.336 \%$ & $-3.178 \%$ & $-1.672 \%$ & $-2.116 \%$ & $-1.049 \%$ \\
\hline
\end{tabular}

However, when we take volatility costs into account, the true alpha of all the funds was negative during the sample period. Ranking of the funds also dramatically changes from Jensen alpha to true net alpha. The correlation coefficient between Jensen Alpha and true alpha among the funds is insignificant, reflecting true alpha brings new information about the performance of the funds. This result suggests that although funds managers are generating alpha, this alpha comes with volatility costs and it is well known in the literature that the terminal wealth of the investors is affected negatively by volatility. To measure the true performance of the active funds, this volatility costs should be adjusted to find the true net alpha, and findings suggest that when it is 
adjusted average alpha goes down from $0.078 \%$ to $-1.34 \%$. Moreover, the volatility cost is not strongly correlated with the Sharpe ratio, Treynor ratio, or information ratios (see details in table 3 in the Appendix). So, the volatility cost is not captured by those ratios sufficiently well.

\section{Conclusion}

In this research, I have attempted to quantify the idiosyncratic volatility of the active management and then show that the effect of higher residual variance due to imperfect diversification may be better captured as an additional cost of active management rather than the traditional measure of mutual funds' performance such as the Sharpe ratio, the information ratio, and the M-2 measure.

Using data of all the closed-end mutual funds listed with Dhaka Stock Exchange (DSE) from 2012 to 2019, I have attempted to quantify this higher idiosyncratic volatility as an additional expense on the portfolio and then estimate true expense ratio and true net alpha of the actively managed funds as a new measure for imperfect portfolio diversification. The study finds that mean volatility cost of the funds is $1.42 \%$ which is on an average around $89 \%$ of the explicit expense ratio and the finding that volatility costs are not strongly correlated with other performance measures such as Sharpe, Treynor or information ratios provides additional information about the fund performance. Moreover, when volatility cost is adjusted to traditional Jensen alpha measure to find a true net alpha of the funds, rankings of the funds significantly change and two alpha measures are not strongly positively correlated, suggesting new information about the fund performance. The findings of the study conclude that the true cost of imperfect diversification can be better captured by considering both explicit expense ratios and implicit expense ratio measured as volatility costs and net alpha reported to the investors should consider the cost of imperfect diversification to better understand the performance of the active fund managers.

\section{References}

Amihud, Y., \& Goyenko, R. (2013). Mutual fund's R2 as predictor of performance. The Review of Financial Studies, 26(3), 667-694. https://doi.org/10.1093/rfs/hhs182

Berk, J. B., \& Green, R. C. (2004). Mutual fund flows and performance in rational markets. Journal of Political Economy, 112(6), 1269-1295. https://doi.org/10.1086/424739

Carhart, M. M. (1997). On persistence in mutual fund performance. The Journal of Finance, 52(1), 57-82. https://doi.org/10.1111/j.1540-6261.1997.tb03808.x

Cremers, K. M., \& Petajisto, A. (2009). How active is your fund manager? A new measure that predicts performance. The Review of Financial Studies, 22(9), 3329-3365. https://doi.org/10.1093/rfs/hhp057

Cremers, M., Ferreira, M. A., Matos, P., \& Starks, L. (2016). Indexing and active fund management: International evidence. Journal of Financial Economics, 120(3), 539-560. https://doi.org/10.1016/j.jfineco.2016.02.008

Elton, E. J., Gruber, M. J., Das, S., \& Hlavka, M. (1993). Efficiency with costly information: A reinterpretation of evidence from managed portfolios. The Review of Financial Studies, 6(1), 1-22. https://doi.org/10.1093/rfs/6.1.1

Fama, E. F., \& French, K. R. (2010). Luck versus skill in the cross-section of mutual fund returns. The Journal of Finance, 65(5), 1915-1947. https://doi.org/10.1111/j.1540-6261.2010.01598.x

Gruber, M. J. (2011). Another puzzle: The growth in actively managed mutual funds. In Investments And Portfolio Performance (pp. 117-144). https://doi.org/10.1142/9789814335409_0007

Jensen, M. C. (1968). The performance of mutual funds in the period 1945-1964. The Journal of Finance, 23(2), 389-416. 10.2307/2325404

Kacperczyk, M., Sialm, C., \& Zheng, L. (2005). On the industry concentration of actively managed equity mutual funds. The Journal of Finance, 60(4), 1983-2011. https://doi.org/10.1111/j.1540-6261.2005.00785

Malkiel, B. G. (1995). Returns from investing in equity mutual funds 1971 to 1991. The Journal of Finance, 50(2), 549-572. https://doi.org/10.1111/j.1540-6261.1995.tb04795

Pástor, L., \& Stambaugh, R. F. (2002). Mutual fund performance and seemingly unrelated assets. Journal of Financial Economics, 63(3), 315-349.

Pástor, L., \& Stambaugh, R. F. (2012). On the size of the active management industry. Journal of Political Economy, 120(4), 740-781. https://doi.org/10.1016/S0304-405X (02)00064-8 
Pástor, L., Stambaugh, R. F., \& Taylor, L. A. (2015). Scale and skill in active management. Journal of Financial Economics, 116(1), 23-45. https://doi.org/10.1016/j.jfineco.2014.11.008

Pástor, L., Stambaugh, R. F., \& Taylor, L. A. (2017). Do funds make more when they trade more?. The Journal of Finance, 72(4), 1483-1528. https://doi.org/10.1111/jofi.12509

Petajisto, A. (2013). Active share and mutual fund performance. Financial Analysts Journal, 69(4), 73-93. https://doi.org/10.2469/faj.v69.n4.7

Stambaugh, R. F. (2014). Presidential address: Investment noise and trends. The Journal of Finance, 69(4), 1415-1453. https://doi.org/10.1111/jofi.12174

Wermers, R. (2000). Mutual fund performance: An empirical decomposition into stock-picking talent, style, transactions costs, and expenses. The Journal of Finance, 55(4), 1655-1695. https://doi.org/10.1111/0022-1082.00263

\section{Appendix}

Table 1. Basic information for mutual funds in the sample as on June 20, 2019

\begin{tabular}{lcccc}
\hline Fund Name & Ticker & Asset Manager & NAV (Million Tk) & Exp Ratio \\
\hline First Janata Bank Mutual Fund & 1JANATAMF & RACE & 3155 & $1.52 \%$ \\
Prime Finance First Mutual Fund & 1STPRIMFMF1 & ICB AMCL & 1275 & $1.49 \%$ \\
AIBL 1st Islamic Mutual Fund & AIBL1STMF & LRG & 1135 & $1.94 \%$ \\
DBH First Mutual Fund & DBH1STMF & LRG & 1352 & $2.00 \%$ \\
EBL First Mutual Fund & EBL1STMF & RACE & 1563 & $1.73 \%$ \\
EBL NRB Mutual Fund & EBLNRBMF & RACE & 2429 & $1.52 \%$ \\
First Bangladesh Fixed Income Fund & FBFIF & RACE & 8535 & $2.38 \%$ \\
Grameen One : Scheme Two & GRAMEENS2 & AIMS & 3597 & $1.03 \%$ \\
Green Delta Mutual Fund & GREENDELMF & LRG & 1683 & $1.84 \%$ \\
ICB AMCL Third NRB Mutual Fund & ICB3RDNRB & ICB AMCL & 1239 & $1.29 \%$ \\
ICB AMCL Second Mutual Fund & ICBAMCL2ND & ICB AMCL & 727 & $1.51 \%$ \\
ICB Employees Provident MF 1: Scheme 1 & ICBEPMF1S1 & ICB AMCL & 910 & $1.54 \%$ \\
IFIC Bank 1st Mutual Fund & IFIC1STMF & RACE & 1977 & $2.33 \%$ \\
IFIL Islamic Mutual Fund-1 & IFILISLMF1 & ICB AMCL & 1151 & $1.48 \%$ \\
LR Global Bangladesh Mutual Fund One & LRGLOBMF1 & LRG & 3294 & $1.64 \%$ \\
MBL 1st Mutual Fund & MBL1STMF & LRG & 1171 & $1.88 \%$ \\
NCCBL Mutual Fund-1 & NCCBLMF1 & LRG & 1165 & $1.97 \%$ \\
NLI First Mutual Fund & NLI1STMF & VIPB & 764 & $2.09 \%$ \\
Phoenix Finance 1st Mutual Fund & PF1STMF & ICB AMCL & 730 & $1.64 \%$ \\
PHP First Mutual Fund & PHPMF1 & RACE & 3031 & $1.48 \%$ \\
Popular Life First Mutual Fund & POPULAR1MF & RACE & 3261 & $1.47 \%$ \\
Prime Bank 1st ICB AMCL Mutual Fund & PRIME1ICBA & ICB AMCL & 1212 & $1.57 \%$ \\
RELIANCE 1sr Mutual Fund & RELIANCE1 & AIMS & 824 & $1.94 \%$ \\
Southeast Bank 1st Mutual Fund & SEBL1STMF & VIPB & 1414 & $1.84 \%$ \\
Trust Bank 1st Mutual Fund & TRUSTB1MF & RACE & 3340 & $1.44 \%$ \\
\hline
\end{tabular}

Table 2. Results for sample of active funds based on the nine year sample (January 2005 -June 2019). All numbers have been annualized.as on June 20, 2019

\begin{tabular}{|c|c|c|c|c|c|}
\hline Fund Ticker Symbol & Exp Ratio (\%) & Vol Cost (\%) & Vol Cost/Expense & Ratio & Total Exp Ratio (\%) \\
\hline 1JANATAMF & $1.52 \%$ & $1.04 \%$ & $68.19 \%$ & & $2.56 \%$ \\
\hline 1STPRIMFMF1 & $1.49 \%$ & $3.60 \%$ & $241.65 \%$ & & $5.09 \%$ \\
\hline AIBL1STMF & $1.94 \%$ & $1.88 \%$ & $97.02 \%$ & & $3.82 \%$ \\
\hline DBH1STMF & $2.00 \%$ & $1.40 \%$ & $70.31 \%$ & & $3.40 \%$ \\
\hline EBL1STMF & $1.73 \%$ & $0.91 \%$ & $52.64 \%$ & & $2.64 \%$ \\
\hline EBLNRBMF & $1.52 \%$ & $1.29 \%$ & $84.75 \%$ & & $2.81 \%$ \\
\hline FBFIF & $2.38 \%$ & $0.79 \%$ & $33.03 \%$ & & $3.16 \%$ \\
\hline GRAMEENS2 & $1.03 \%$ & $1.55 \%$ & $150.21 \%$ & & $2.57 \%$ \\
\hline GREENDELMF & $1.84 \%$ & $1.75 \%$ & $95.23 \%$ & & $3.60 \%$ \\
\hline
\end{tabular}




\begin{tabular}{lllll}
\hline ICB3RDNRB & $1.29 \%$ & $1.44 \%$ & $111.69 \%$ & $2.73 \%$ \\
ICBAMCL2ND & $1.51 \%$ & $1.81 \%$ & $119.83 \%$ & $3.33 \%$ \\
ICBEPMF1S1 & $1.54 \%$ & $1.61 \%$ & $104.94 \%$ & $3.15 \%$ \\
IFIC1STMF & $2.33 \%$ & $1.05 \%$ & $45.11 \%$ & $3.38 \%$ \\
IFILISLMF1 & $1.48 \%$ & $1.51 \%$ & $102.35 \%$ & $2.99 \%$ \\
LRGLOBMF1 & $1.64 \%$ & $1.30 \%$ & $79.48 \%$ & $2.94 \%$ \\
MBL1STMF & $1.88 \%$ & $1.30 \%$ & $69.39 \%$ & $3.18 \%$ \\
NCCBLMF1 & $1.97 \%$ & $1.00 \%$ & $50.79 \%$ & $2.98 \%$ \\
NLI1STMF & $2.09 \%$ & $0.70 \%$ & $33.45 \%$ & $2.79 \%$ \\
PF1STMF & $1.64 \%$ & $2.29 \%$ & $139.51 \%$ & $3.94 \%$ \\
PHPMF1 & $1.48 \%$ & $1.82 \%$ & $122.60 \%$ & $3.30 \%$ \\
POPULAR1MF & $1.47 \%$ & $1.56 \%$ & $105.69 \%$ & $3.03 \%$ \\
PRIME1ICBA & $1.57 \%$ & $1.66 \%$ & $105.86 \%$ & $3.23 \%$ \\
RELIANCE1 & $1.94 \%$ & $0.60 \%$ & $31.01 \%$ & $2.54 \%$ \\
SEBL1STMF & $1.84 \%$ & $0.52 \%$ & $28.24 \%$ & $2.36 \%$ \\
TRUSTB1MF & $1.44 \%$ & $1.04 \%$ & $72.29 \%$ & $2.48 \%$ \\
\hline
\end{tabular}

Table 3. Results for sample of active funds based on the nine year sample (January 2005 -June 2019). All numbers have been annualized.as on June 20, 2019

\begin{tabular}{|c|c|c|c|c|c|c|c|c|c|}
\hline $\begin{array}{l}\text { Fund Ticker } \\
\text { Symbol }\end{array}$ & $\alpha$ & $\boldsymbol{\beta}$ & R-Square & $\begin{array}{l}\text { Jensen } \\
\text { Alpha } \\
\end{array}$ & $\begin{array}{c}\text { Vol Cost } \\
(\%)\end{array}$ & $\begin{array}{c}\text { True } \\
\text { Alpha }\end{array}$ & $\begin{array}{c}\text { Sharpe } \\
\text { Ratio }\end{array}$ & $\begin{array}{c}\text { Information } \\
\text { Ratio } \\
\end{array}$ & $\begin{array}{c}\text { Treynor } \\
\text { Ratio } \\
\end{array}$ \\
\hline 1JANATAMF & $-0.21 \%$ & 0.844 & $26 \%$ & $-0.21 \%$ & $1.04 \%$ & $-1.25 \%$ & $-1.45 \%$ & $-2.12 \%$ & $-0.53 \%$ \\
\hline 1STPRIMFMF1 & $0.42 \%$ & 0.991 & $12 \%$ & $0.42 \%$ & $3.60 \%$ & $-3.18 \%$ & $0.26 \%$ & $2.95 \%$ & $0.14 \%$ \\
\hline AIBL1STMF & $0.12 \%$ & 0.501 & $6 \%$ & $0.12 \%$ & $1.88 \%$ & $-1.76 \%$ & $-0.07 \%$ & $2.43 \%$ & $-0.05 \%$ \\
\hline DBH1STMF & $0.22 \%$ & 0.837 & $21 \%$ & $0.22 \%$ & $1.40 \%$ & $-1.19 \%$ & $-0.07 \%$ & $2.90 \%$ & $-0.03 \%$ \\
\hline EBL1STMF & $0.11 \%$ & 0.726 & $23 \%$ & $0.11 \%$ & $0.91 \%$ & $-0.80 \%$ & $-0.35 \%$ & $2.54 \%$ & $-0.14 \%$ \\
\hline EBLNRBMF & $-0.18 \%$ & 0.858 & $23 \%$ & $-0.18 \%$ & $1.29 \%$ & $-1.48 \%$ & $-1.27 \%$ & $-1.66 \%$ & $-0.50 \%$ \\
\hline FBFIF & $-0.28 \%$ & 0.483 & $13 \%$ & $-0.28 \%$ & $0.79 \%$ & $-1.07 \%$ & $-1.67 \%$ & $-1.81 \%$ & $-0.87 \%$ \\
\hline GRAMEENS2 & $0.28 \%$ & 0.892 & $21 \%$ & $0.28 \%$ & $1.55 \%$ & $-1.26 \%$ & $0.07 \%$ & $3.31 \%$ & $0.03 \%$ \\
\hline GREENDELMF & $0.36 \%$ & 0.832 & $17 \%$ & $0.36 \%$ & $1.75 \%$ & $-1.39 \%$ & $0.32 \%$ & $4.03 \%$ & $0.15 \%$ \\
\hline ICB3RDNRB & $-0.18 \%$ & 0.763 & $17 \%$ & $-0.18 \%$ & $1.44 \%$ & $-1.62 \%$ & $-1.15 \%$ & $-1.22 \%$ & $-0.52 \%$ \\
\hline ICBAMCL2ND & $0.13 \%$ & 0.979 & $22 \%$ & $0.13 \%$ & $1.81 \%$ & $-1.68 \%$ & $-0.38 \%$ & $1.33 \%$ & $-0.15 \%$ \\
\hline ICBEPMF1S1 & $-0.21 \%$ & 0.796 & $17 \%$ & $-0.21 \%$ & $1.61 \%$ & $-1.82 \%$ & $-1.19 \%$ & $-1.56 \%$ & $-0.55 \%$ \\
\hline IFIC1STMF & $0.10 \%$ & 0.780 & $23 \%$ & $0.10 \%$ & $1.05 \%$ & $-0.95 \%$ & $-0.41 \%$ & $2.04 \%$ & $-0.16 \%$ \\
\hline IFILISLMF1 & $0.60 \%$ & 0.885 & $21 \%$ & $0.60 \%$ & $1.51 \%$ & $-0.91 \%$ & $0.95 \%$ & $6.78 \%$ & $0.39 \%$ \\
\hline LRGLOBMF1 & $-0.34 \%$ & 0.441 & $7 \%$ & $-0.34 \%$ & $1.30 \%$ & $-1.64 \%$ & $-1.49 \%$ & $-1.92 \%$ & $-1.05 \%$ \\
\hline MBL1STMF & $-0.25 \%$ & 0.493 & $9 \%$ & $-0.25 \%$ & $1.30 \%$ & $-1.55 \%$ & $-1.25 \%$ & $-1.16 \%$ & $-0.80 \%$ \\
\hline NCCBLMF1 & $-0.19 \%$ & 0.538 & $13 \%$ & $-0.19 \%$ & $1.00 \%$ & $-1.20 \%$ & $-1.23 \%$ & $-0.75 \%$ & $-0.64 \%$ \\
\hline NLI1STMF & $0.20 \%$ & 0.303 & $6 \%$ & $0.20 \%$ & $0.70 \%$ & $-0.50 \%$ & $0.49 \%$ & $5.37 \%$ & $0.37 \%$ \\
\hline PF1STMF & $0.19 \%$ & 0.896 & $15 \%$ & $0.19 \%$ & $2.29 \%$ & $-2.10 \%$ & $-0.14 \%$ & $1.95 \%$ & $-0.07 \%$ \\
\hline PHPMF1 & $0.41 \%$ & 0.976 & $21 \%$ & $0.41 \%$ & $1.82 \%$ & $-1.41 \%$ & $0.32 \%$ & $4.04 \%$ & $0.13 \%$ \\
\hline POPULAR1MF & $0.36 \%$ & 0.872 & $20 \%$ & $0.36 \%$ & $1.56 \%$ & $-1.20 \%$ & $0.29 \%$ & $4.15 \%$ & $0.12 \%$ \\
\hline PRIME1ICBA & $-0.08 \%$ & 0.939 & $22 \%$ & $-0.08 \%$ & $1.66 \%$ & $-1.74 \%$ & $-0.91 \%$ & $-0.63 \%$ & $-0.37 \%$ \\
\hline RELIANCE1 & $0.04 \%$ & 0.787 & $35 \%$ & $0.04 \%$ & $0.60 \%$ & $-0.56 \%$ & $-0.74 \%$ & $1.65 \%$ & $-0.24 \%$ \\
\hline SEBL1STMF & $0.27 \%$ & 0.182 & $3 \%$ & $0.27 \%$ & $0.52 \%$ & $-0.25 \%$ & $1.12 \%$ & $7.10 \%$ & $1.18 \%$ \\
\hline TRUSTB1MF & $0.06 \%$ & 0.927 & $30 \%$ & $0.06 \%$ & $1.04 \%$ & $-0.98 \%$ & $-0.64 \%$ & $1.03 \%$ & $-0.22 \%$ \\
\hline
\end{tabular}

\section{Copyrights}

Copyright for this article is retained by the author(s), with first publication rights granted to the journal.

This is an open-access article distributed under the terms and conditions of the Creative Commons Attribution license (http://creativecommons.org/licenses/by/4.0/). 